\title{
The Relationship between Force and Time with Lagrange Formula by Regulating Piston Mass on Crank Linkage of Vehicle
}

\author{
Run Xu, Boyong Hur
}

Gyeongsang National University, Metallurgical Engineering Dept, Jin Chu 52828, Korea

DOI: $10.36348 /$ sjet.2021.v06i04.005 $\quad$ | Received: 17.03.2021 | Accepted: 25.04.2021 | Published: 27.04.2021

*Corresponding author: Boyong Hur

\section{Abstract}

In this study the simulation about force and time is built with Lagrange equation which solves the crankshaft dynamics in engine of vehicle. The force will incline as the time inclines with a certain mass of piston of $1.6 \mathrm{Kg}, 3.2 \mathrm{Kg} \& 4.8 \mathrm{Kg}$ in engine on vehicle, meantime as the mass inclines the force will incline too from $16 \mathrm{~N}$ and $32 \mathrm{~N}$ to $48 \mathrm{~N}$ with maximum value at $7 \mathrm{E}-3 \mathrm{~s}$ at $700 \mathrm{r} / \mathrm{m}$ rotation of engine. The bad force will be formed in first and then the good one will be followed at last in terms of former $\mathrm{d}^{2} \mathrm{~F} / \mathrm{dt}^{2}<0$ and $\mathrm{d}^{2} \mathrm{~F} / \mathrm{dt}^{2}>0$ respectively. But the bad force has good stability. If the mass of piston is increased the bigger force may be formed in engine.

Keywords: Relationship; Force And Time; Lagrange Equation; Crank Shaft; Crank; Crank Linkage;Vehicle.

Copyright () 2021 The Author(s): This is an open-access article distributed under the terms of the Creative Commons Attribution 4.0 International License (CC BY-NC 4.0) which permits unrestricted use, distribution, and reproduction in any medium for non-commercial use provided the original author and source are credited.

\section{INTRODUCTION}

The crank shaft is an important mechanism in vehicle which includes crank, crank linkage and piston on engine so the research will be preceded on them is necessary method to calculate with modeling in recent study. So this paper will search the detail database to establish the equation to solve it further. [1-3] the dynamics can solve the key problem of intrinsic relationship between force and time in engine which can express the detail behavior to the crank shaft force analysis for us to find intrinsic things.

As recent the vehicle has been grown rapidly in world so the most significant engine part of crank shaft will play more and more roles in future. The fatigue life will be key to its span life so the force change with time of rotation will be important data for us to search deeply. The force behavior must be established to further clarify the fatigue role and play a key role. Since the time limits the fatigue life wouldn't be searched here we only play to establish dynamic modelling in terms of Lagrange equation to crank shaft mechanism. We try to find role of force formed on piston mass at certain rotation speed and time in order to find its maximum force and its stability.

We want to find the mass condition which causes the bigger force for engine of crankshaft so it is searched on its status in this study. On the other side the shaft rotation is studied too to look for the appropriate effects.

\section{Modeling and Calculation}

According to Figure 1 and 2 which is kinematic graphs on the crankshaft in engine in vehicle, From Figure 2 it is supposes that crank $\mathrm{R}=60 \mathrm{~mm}$, crank linkage $\mathrm{L}=210 \mathrm{~mm}$. This is the engine driving crankshaft, $\Delta \Delta \mathrm{l}=\mathrm{lmax}-\mathrm{lmin}$. A is piston and cylinder wall; $\mathrm{v}$ is its speed; $\mathrm{n}$ is shaft rotation.

It has

$\Delta l=\sqrt{L^{2}+R^{2}-2 L R \cos \left[\pi-\arcsin \left(\frac{R}{L} \sin \theta_{1}\right)-\theta_{1}\right]}$

Here $\theta_{1}=2 \pi n t / 60$.

According to Lagrange equation

$\frac{d}{d t}\left(\frac{\partial E_{K}}{\partial \dot{q}_{i}}\right)-\frac{\partial E_{K}}{\partial q_{i}}+\frac{\partial E_{P}}{\partial q_{i}}=F_{i}$

The equation (2) is the crank shaft dynamic equation in terms of Figure 2. Here rotary inertia is

$I_{1}=\frac{1}{3} m_{1} l_{1}^{2} ; I_{2}=\frac{1}{3} m_{2} l_{2}^{2}$ 
It is supposed that $\mathrm{m}_{1}=0.6 \mathrm{Kg} ; \mathrm{m}_{2}=1 \mathrm{Kg} ; \mathrm{m}_{3}=0.25 \mathrm{Kg}$.

And $\omega 1 \mathrm{t}=\theta \quad 1 \ldots$

So it has $\omega_{-}^{\cdot} \overline{1}_{--t^{\wedge}} 2 \theta_{-}$

The same as above it has

$\omega^{*} 2=-t^{\wedge} 2 \theta 2$

$\omega \cdot \overline{3}=-\mathrm{t}^{\wedge} 2 \theta \overline{3}$

And $v_{-}^{*} 3=-\mathrm{t}^{\wedge} 2[\Delta \mathrm{l}-(\mathrm{L}-\mathrm{R})]$

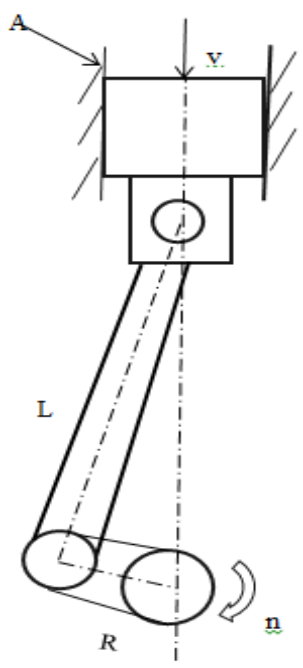

Fig-1: The kinematic of crankshaft linkage length in the engine of vehicle.

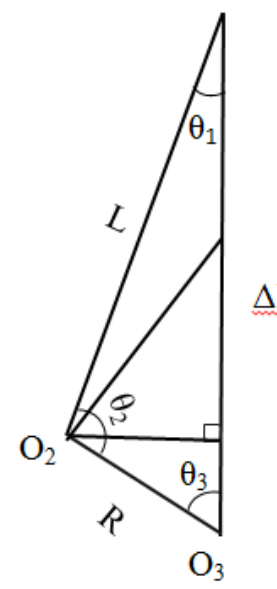

Fig-2: The kinematic of crankshaft linkage mechanism in engine of vehicle.

\section{DISCUSSIONS}

In Fig-3 the curve will be seperated two parts where one is $\mathrm{d}^{2} \mathrm{~F} / \mathrm{dt}^{2}>0$ as seen in right which expresses it has the minimum point and the other is $\mathrm{d}^{2} \mathrm{~F} / \mathrm{dt}^{2}<0$ in left which expresses that it has maximum one. That said that the steep inclining first and the sluggish inclining at last and it expresses that the big force is formed first in a cycle so it has been paid attention to the big force which may cause grinding heavily in first angles. The force will incline as the time is big. With the maximum $0 \sim 1.6 \mathrm{Kg}$ distribution will cause the small force $16 \mathrm{~N}$ too. In Figure 4and 5 the curve will incline the force to
$32 \mathrm{~N}$ and $48 \mathrm{~N}$ respectively with the $0 \sim 3.2 \mathrm{Kg}$ and $0 \sim 4.8 \mathrm{Kg}$ at the $7 \mathrm{E}-3 \mathrm{~s}$ and $700 \mathrm{r} / \mathrm{m}$.

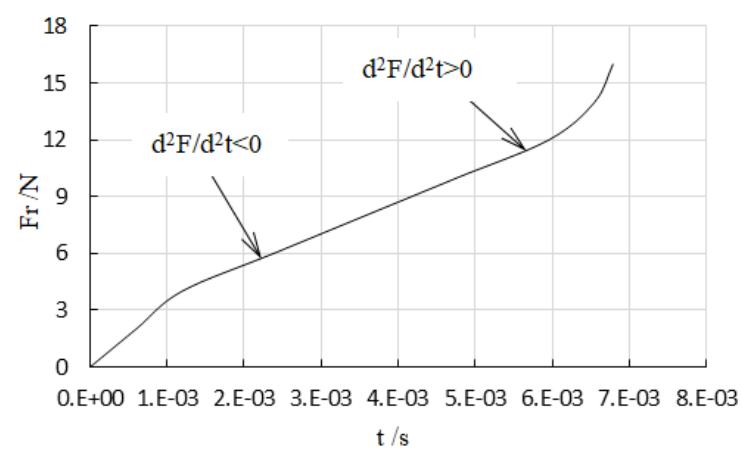

Fig-3: The relationship between force and time in crank shaft with rotation of $700 \mathrm{r} / \mathrm{m}$ and $0-1.6 \mathrm{Kg}$ mass piston on vehicle.

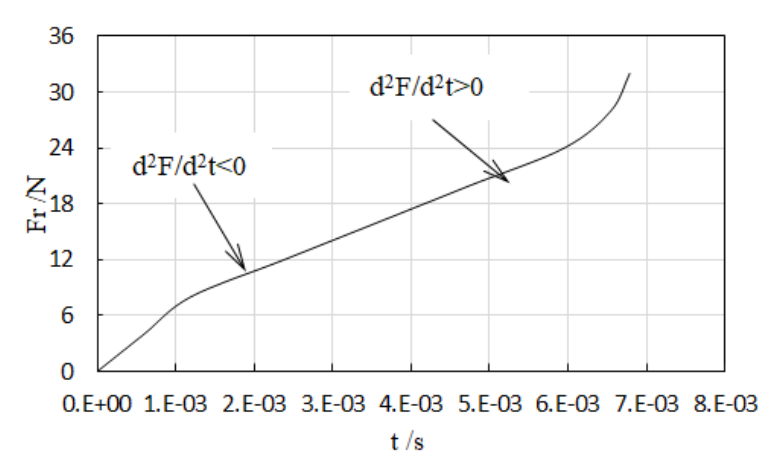

Fig-4: The relationship between force and time in crank shaft with the rotation of $700 \mathrm{r} / \mathrm{m}$ and regulating from 0 to $3.2 \mathrm{Kg}$ mass piston on vehicle.

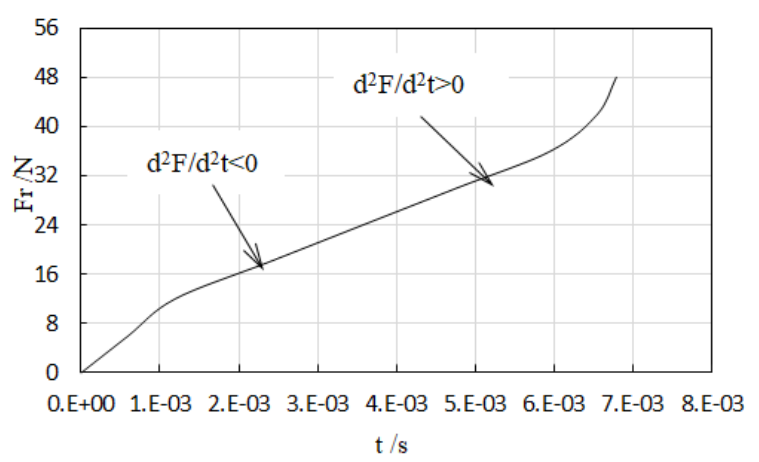

Fig-5: The relationship between force and time in crank shaft with the rotation of $700 \mathrm{r} / \mathrm{m}$ and regulating from 0 to $4.8 \mathrm{Kg}$ mass piston on vehicle.

Fig-5: shows the curve between force and time under $\mathrm{n}=700 \mathrm{r} / \mathrm{m}$. This indicates that the maximum force in the engine is up to $48 \mathrm{~N}$ ie. $5 \mathrm{KgF}$ and the force inclines steep first and inclines in engine with the increase of time. It is no relation to the crank length $\mathrm{R}=60 \mathrm{~mm}$ and linkage $\mathrm{L}=210 \mathrm{~mm}$ in terms of supposed conditions with the calculation result. The periodic time is $7 \mathrm{E}-3 \mathrm{~s}$ in $700 \mathrm{r} / \mathrm{m}$, it means that the periodic time is the same. Figure 5 shows that the force becomes sinusoidal 
likely from 0 to $7 \mathrm{E}-3 \mathrm{~s}$ which is the same as $\theta_{2}=0 \sim 57^{\circ}$. The size is larger than the one at $3.2 \mathrm{Kg}$. And $1.6 \mathrm{Kg}$. The force is larger than the above two. The force is used instantaneous time within one cycle to gain the simulation results.

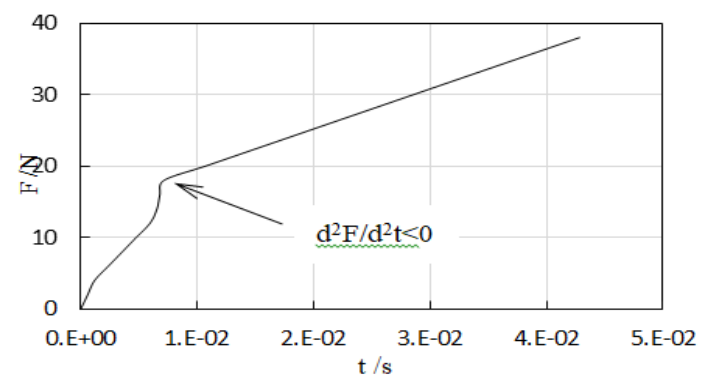

Fig-6: The relationship between force and time in crank shaft with the rotation of $700 \mathrm{r} / \mathrm{m}$ and regulating from 0 to $3.8 \mathrm{Kg}$ mass piston on vehicle.

In Fig- 6 the force will be the same as the same as Figure 3 in one cycle of crank angle. It is found that the inclining trend may be gained in this cycle. The maximum force can be beyond $3.5 \mathrm{Kg}$ at the end of $4.3 \mathrm{E}-2 \mathrm{~s}$. The same trends with this figure are gained in Figure $7 \& 8$ except that the inclining force will be formed here. For example the biggest one will attain $75 \mathrm{~N}$ and $110 \mathrm{~N}$ at the end of $4.3 \mathrm{E}-2 \mathrm{~s}$. It expresses that the force with mass piston inclining to $7.6 \mathrm{Kg} \& 11.4 \mathrm{Kg}$ may incline too. The turn points in these figures range from $18 \mathrm{~N}$ to $37 \mathrm{~N}, 55 \mathrm{~N}$ which explains that the force will be inclined two times.

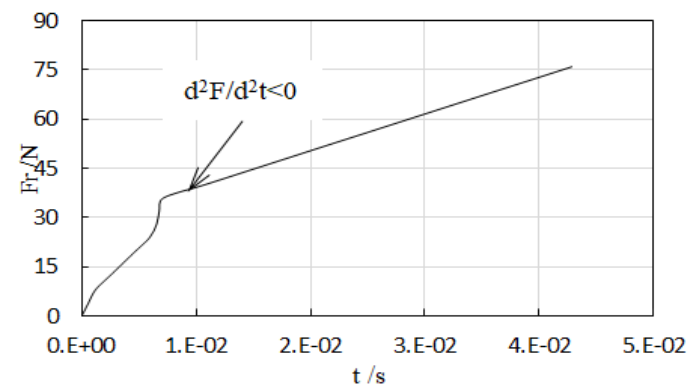

Fig-7: The relationship between force and time in crank shaft with the rotation of $700 \mathrm{r} / \mathrm{m}$ and $7.6 \mathrm{Kg}$ mass piston on vehicle.

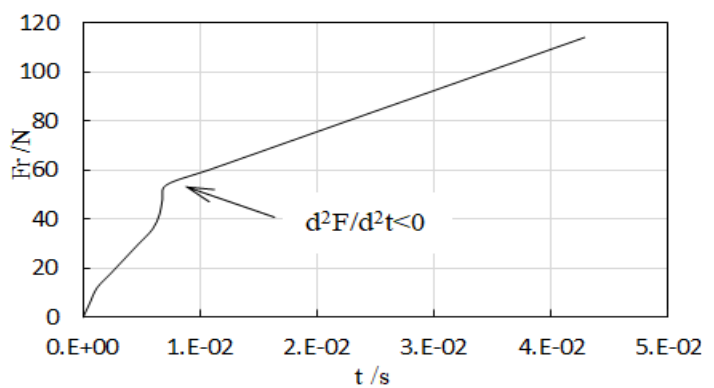

Fig-8: The relationship between force and time in crank shaft with the rotation of $700 \mathrm{r} / \mathrm{m}$ and $11.4 \mathrm{Kg}$ mass piston on vehicle.
In short the steep force can be formed first and then form the sluggish one in a cycle meantime the big grind can be formed and them the small one. The former will damage fatigue and the later will benefit to it. The bad one will be known first and the good will be gained later in terms of former $\mathrm{d}^{2} \mathrm{~F} / \mathrm{dt}^{2}<0$ and $\mathrm{d}^{2} \mathrm{~F} / \mathrm{dt}^{2}>0$ respectively. The curve will express the summit like in Figure 6 8. Due to $\mathrm{d}^{2} \mathrm{~F} / \mathrm{dt}^{2}<0$ the bad linear curve has been formed.

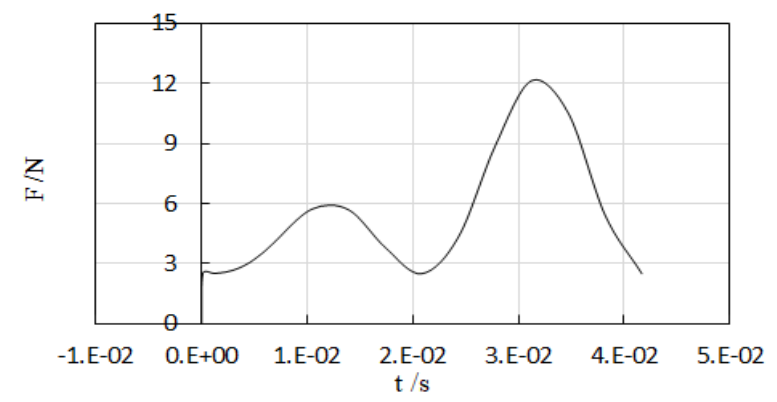

Fig-9: The relationship between force and time in crankshaft with the rotation of $720 \mathrm{r} / \mathrm{m}$ and constant $0.2 \mathrm{Kg}$ mass piston on vehicle.

In Fig-10 the force will distribute into two sinusoidal waves. They are different with amplitude. The first one exhibits $3 \mathrm{~N}$ whilst the second is $9 \mathrm{~N}$ within a cycle. The force may decline as the rotation speed inclines from $12 \mathrm{~N}$ and $11 \mathrm{~N}$ to $10 \mathrm{~N}$. they exhibit the summit with 1.1E-2 and from bigger to smaller than $3 \mathrm{E}$ $2 \mathrm{~s}$ in terms of Figure 9 11. the second summit may be larger than first one reaching the biggest value.

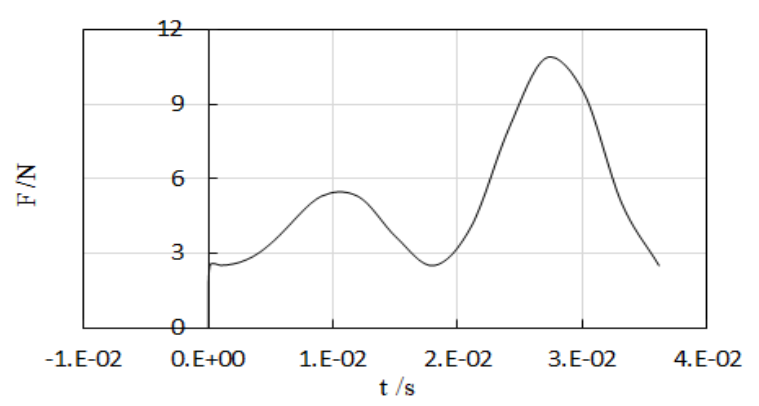

Fig-10: The relationship between force and time in crankshaft with the rotation of $830 \mathrm{r} / \mathrm{m}$ and $0.2 \mathrm{Kg}$ mass piston on vehicle.

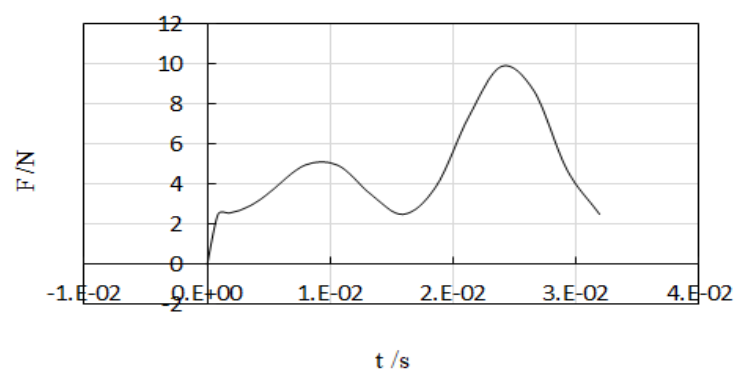

Fig-11: The relationship between force and time in crankshaft with the rotation of $940 \mathrm{r} / \mathrm{m}$ and $0.2 \mathrm{Kg}$ mass piston on vehicle. 


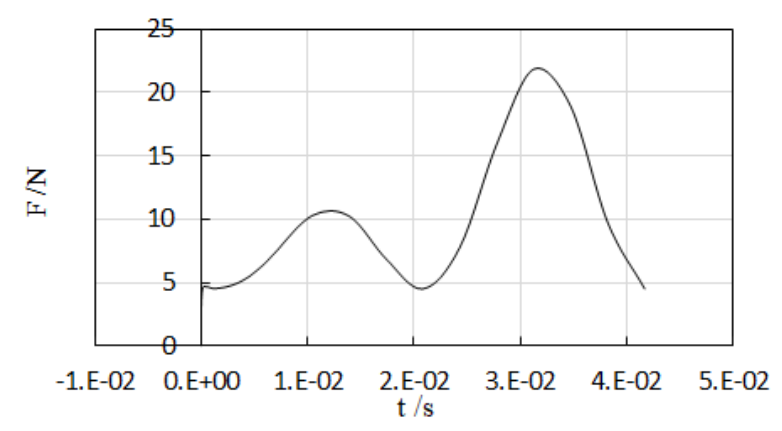

Fig-12: The relationship between force and time in crankshaft with the rotation of $940 \mathrm{r} / \mathrm{m}$ and $0.45 \mathrm{Kg}$ mass piston on vehicle.

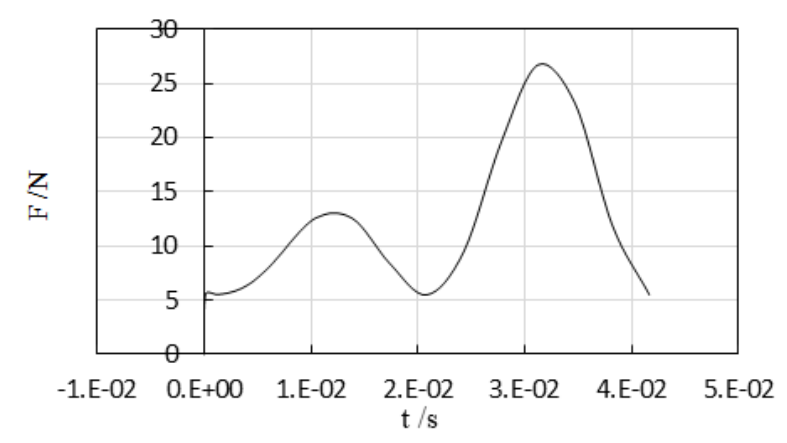

Fig-13: The relationship between force and time in crankshaft with the rotation of $940 \mathrm{r} / \mathrm{m}$ and $0.55 \mathrm{Kg}$ mass piston on vehicle.

In Fig-12 and 13 the force may incline to $22 \mathrm{~N}$ and $27 \mathrm{~N}$ under the condition of $0.45 \mathrm{Kg}$ and $0.55 \mathrm{~kg}$ of piston respectively. It expresses that the bigger piston mass can form the high force.
In general the force of piston may be inclined through declining the rotation and inclining its mass. In details the demanded one may be reached with big size if there are defined requirement. The second one is playing important role so it can be increased by the heavy piston.

\section{CONCLUSIONS}

With increasing time the corresponding angle will increase to $57^{\circ}$ which is benefit to stroke stability. With the increase of time and the crank linkage angle with the force becomes big which shows sinusoidal wave. When crank and linkage length is no big relation to the force. The force will increase when the rotation increases and periodic decreases. The force attains $46 \mathrm{~N}$ at $\mathrm{n}=700 \mathrm{r} / \mathrm{m}$ with $0 \sim 4.6 \mathrm{Kg}$ while it attains $16 \mathrm{~N}$ with $0 \sim 1.6 \mathrm{~K}$ at the same speed. If the mass of piston is increased the bigger one may be formed.

\section{REFERENCES}

1. Li jingmin, zhao lanying, liu song, ren sihang et al., (2008). Dynamic simulation analysis of crank linkage length mechanism of type 4100 internal combustion engine, Equipment Manufacturing Technology, 12(6).

2. Yang,G., (2015). The Plastic Dynamics in Genenral [M], Tsinghua Univer Press, 133.

3. Faculty of theoretical mechanics in Harbin Institute of Technology.(2011) Theoretical mechanics I[M], Higher Education Press, 267. 